\title{
Matrix Metalloproteinase-1 Genotype Contributes to the Risk of Non-solid Tumor in Childhood Leukemia
}

\author{
JEN-SHENG PEI ${ }^{1 *}$, PEI-CHEN HSU $^{1 *}$, AN-KUO CHOU $^{2 *}$, CHIA-WEN TSAI $^{3}$, WEN-SHIN CHANG ${ }^{3}$, \\ CHIEH-LUN HSIAO ${ }^{3,4}$, YUAN-NIAN HSU ${ }^{5}$, SHUN-PING CHENG $^{6}$ and DA-TIAN BAU ${ }^{3,4,7}$ \\ Departments of ${ }^{1}$ Pediatrics, ${ }^{5}$ Family Medicine, and ${ }^{6}$ Physical Medicine and Rehabilitation, \\ Taoyuan General Hospital, Ministry of Health and Welfare, Taoyuan, Taiwan, R.O.C.; \\ ${ }^{2}$ Department of Anesthesiology, and ${ }^{3}$ Terry Fox Cancer Research Laboratory, \\ China Medical University Hospital, Taichung, Taiwan, R.O.C.; \\ ${ }^{4}$ Graduate Institute of Clinical Medical Science, China Medical University, Taichung, Taiwan, R.O.C.; \\ ${ }^{7}$ Department of Bioinformatics and Medical Engineering, Asia University, Taichung, Taiwan, R.O.C.
}

\begin{abstract}
Aim: Up-regulation of metalloproteinase (MMPs) proteins have been shown in various types of solid cancers and the genotype of MMP1 has been associated with the risk of solid cancers. However, the contribution of MMP1 genotype to leukemia has never been investigated to our knowledge. Therefore, in this study we aimed to evaluate the contribution of the genotypic variants in the promoter region of MMP1 to childhood acute lymphoblastic leukemia (ALL) risk in Taiwan. Materials and Methods: In this case-control study, 266 patients with childhood ALL and 266 non-cancer controls were genotyped by polymerase chain reactionrestriction fragment length polymorphism methodology. Results: The distribution of $2 G / 2 G, 1 G / 2 G$ and $1 G / 1 G$ for MMP1 promoter rs1799750 genotype was $49.2 \%, 39.5 \%$ and $11.3 \%$ in the childhood ALL group and $36.8 \%, 43.6 \%$ and $19.5 \%$ in the non-cancer control group, respectively ( $p$ for trend=0.0046), significantly differentially distributed between childhood ALL and control groups. The carrier comparisons in dominant and recessive models also support the findings that $1 G$ appears to be the protective allele in childhood ALL. In genotype and gender interaction analysis, it was found that boys carrying the MMP1 rs $17997501 G / 2 G$ or $1 G / 1 G$ genotypes had lower odds ratios(ORs) of 0.68 and
\end{abstract}

\footnotetext{
*These Authors contributed equally to this study.

Correspondence to: Da-Tian Bau, Terry Fox Cancer Research Laboratory, Department of Medical Research, China Medical University Hospital, 2 Yuh-Der Road, Taichung, 404 Taiwan, R.O.C. Tel: +886 422052121 Ext.7534, e-mail: datian@mail.cmuh.org.tw; artbau2@gmail.com
}

Key Words: Childhood leukemia, MMP1, genotype, polymorphism, Taiwan.
0.43 [95\% confidence intervals $(C I)=0.47-0.98$ and 0.26 $0.73, p=0.0395$ and 0.0013 , respectively] for childhood $A L L$ than those carrying the $2 G / 2 G$ genotype. Analysis of genotype inaction with age of onset age showed those aged less than 3.5 years at onset carrying the $1 G / 2 G$ or $1 G / 1 G$ genotypes had lower ORs (0.0183 and 0.0004, respectively) for childhood ALL, but there was no such difference for those having an age at onset of 3.5 years or more. Conclusion: Our results indicate that the MMP1 rs1799750 $1 \mathrm{G}$ allele is a protective biomarker for childhood ALL.

Globally, acute lymphoblastic leukemia (ALL) is the most common pediatric leukemia and accounts for $25-30 \%$ of childhood malignancies $(1,2)$. Statistically, the annual worldwide incidence rate of childhood ALL is approximately 10 newly diagnosed cases per 100,000 , with a peak incidence occurring at the age of 2 to 5 years (3). Although the clinical, pathological and immunophenotypic features of ALL are well documented, its etiology has not been fully clarified. From the epidemiological viewpoint, several factors, such as ionizing radiation, parental use of alcohol and tobacco, and viral exposure, have been identified as potential risk factors for the development of childhood ALL. But among these factors, only ionizing radiation has been confirmed regarding its mechanism of action in the etiology of leukemia (4). In recent years, more and more reports have supported the concept that genomic factors may play a role in the initiation and development of childhood ALL. Firstly, Down syndrome and Fanconi anemia, two well-known inherited genetic disorders, have been associated with an elevated risk for ALL $(5,6)$. Secondly, genetic mutations in several typical cancer-related genes, such as $p 53$, neuroblastoma RAS viral oncogene homolog $(N R A S)$, and PHD finger protein 6 (PHF6), have frequently been identified in patients with ALL (7). Thirdly, only a small proportition of children with 
ALL have a history of been exposed to these factors, indicating the potential role for a genetic predisposition in the etiology of ALL, especially childhood ALL (2).

The matrix metalloproteinases (MMPs), also known as matrixins, are a family of proteases that play a key role in extracellular matrix component regulation by their action in degradation of various connective tissue matrices $(8,9)$. Homeostasis of each MMP is also a dynamic balance of a complicated network through interactions with other members and their specific inhibitors, e.g. the tissue inhibitors of metalloproteinases (TIMPs) (9). MMP1, also known as collagenase- 1 , is most abundant among the MMPs and under the control of activator protein-1 (AP1), which binds to the promoter region of mitogen-activated kinase through polyomavirus-enhancing activity-3 $(10,11)$. In 2016 , a polymorphic variation was found in the $M M P 1$ promoter region at upstream position 1,607 bp (rs1799750, also known as rs11292517, rs 17886084, rs61633513, rs139258005, rs375359915 and rs368625565), which controls the transcriptional activity of $M M P 1$ and was associated with the incidence and progression of several types of cancer, including oral (12), breast (13), ovarian (14), lung (15), esophageal $(16,17)$, gastric (18) and colorectal (19).

The genomic contribution of MMP1 to ALL has not been well elucidated. The purpose of this study was to reveal the contribution of MMP1 genotype at the promoter -1607 site to the risk of ALL in a representative pediatric population sample (controls/cases=266/266) of Taiwanese children.

\section{Materials and Methods}

Study population and sample collection. Our study was approved by the Institutional Review Board of China Medical University Hospital, and written informed consent was obtained from one or both parents of all participants. Two hundred and sixty-six patients diagnosed with childhood ALL (all patients under 18 years of age) were recruited between 2005-2010 from the General Surgery outpatient clinics within the Pediatric Departments at the China Medical University Hospital and the National Taiwan University Hospital, Taiwan, Republic of China. All of the clinical characteristics of these patients, including their histological details, were identified by expert surgeons. All children voluntarily participated, completed a questionnaire with the help of parents or guardians, and provided peripheral blood samples. The questionnaire recorded their disease history, diet and sleeping habit, and the disease history, diet, behavioral lifestyle and socialeconomic status of the parents. An equal number of age-matched non-cancer healthy volunteers were selected for use as a control group following initial random sampling from the Health Examination Cohort established from 2005 to 2010 as previously published (20-22). The registered health practitioners in the hospital provide a multidisciplinary team approach of health assessment for the volunteers. Most of the volunteers underwent health examinations every 5 to 6 months. A total of 457 volunteers age under 18 years were recruited into this study and chosen were cancer free by the age at diagnosis of the case child with the
International Classification of Disease, ninth revision (ICD-9) codes (defined by World Health Organization). Finally, 266 participants were included for analysis in the study since to match the population structure (number, age and gender) with our case population. The overall agreement rate in the study was above $85 \%$.

Genotyping assays. Genomic DNA was prepared from peripheral blood leukocytes using a QIAamp Blood Mini Kit (Blossom, Taipei, Taiwan), stored long-term at $-80^{\circ} \mathrm{C}$, diluted and aliquoted for genotyping as a working stock at $-20^{\circ} \mathrm{C}(23,24)$. The sequences of primers and the restriction enzymes for $M M P 1$ promoter -1607 genotyping are the same as our recently published MMP1 rs1799750 genotyping methodology $(12,13)$. The forward and reverse primers were 5'-TGACTTTTAAAACATAGTCTATGT-3' and 5'-GATTGATTTGAGATAAGTCATAGC-3', respectively. The polymerase chain reaction (PCR) cycling conditions were: one cycle at $94^{\circ} \mathrm{C}$ for $5 \mathrm{~min} ; 35$ cycles of $94^{\circ} \mathrm{C}$ for $30 \mathrm{~s}, 58^{\circ} \mathrm{C}$ for $30 \mathrm{~s}$, and $72^{\circ} \mathrm{C}$ for $30 \mathrm{~s}$; and a final extension at $72^{\circ} \mathrm{C}$ for $10 \mathrm{~min}$. After amplification, the PCR products were subject todigestion by $A l u \mathrm{I}$ restriction endonuclease for $2 \mathrm{~h}$ at $37^{\circ} \mathrm{C}$ and separation using $3 \%$ agarose gel electrophoresis. The genotypes were identified as homozygous $2 \mathrm{G} / 2 \mathrm{G}$ with 269 -bp product, heterozygous $1 \mathrm{G} / 2 \mathrm{G}$ with 269-, 241- and 28-bp products, and homozygous $1 \mathrm{G} / 1 \mathrm{G}$ with 241and 28-bp products. All the genotypic processing was repeated by two researchers independently, and blindly, and the results were $100 \%$ concordant. In addition, the success rate of PCR-restrictive fragment length polymorphism (RFLP) is $100 \%$, and the genotypes of $5 \%$ of the participants in both the control and patient groups were analyzed by PCR direct sequencing (Genomics BioSci \& Tech Co., Taipei, Taiwan). The concordance between direct sequencing and PCR-RFLP was $100 \%$.

Statistical analyses. Those participants having both genotypic and clinical data (controsl/cases=266/266) were selected for final analysis. The descriptive statistics of patients and controls are presented as the mean and standard deviation (SD) or as percentages. The Pearson's chi-square test or Fisher's exact test (when any cell was less than five) was used to compare the distribution of the genotypes. Associations were evaluated as odds ratios (ORs) with $95 \%$ confidence intervals (CIs). Statistical tests were deemed significant when the $p$-value was less than 0.05 .

\section{Results}

The frequency distributions for the age and gender of 266 patients with childhood ALL and 266 non-cancer healthy controls are shown in Table I. The data showed that the age and gender of the cases and controls were indeed both well matched in these two groups $(p>0.05)$ (Table I).

The genotypic analysis for the MMP1 rs1799750 among the controls and patients are shown in Table II. The genotypic frequency distributions for MMPI rs1799750 were significantly different between childhood ALL and control groups ( $\mathrm{p}$ for trend=0.0046) (Table II). In detail, the $M M P 1$ rs1799750 heterozygous $1 \mathrm{G} / 2 \mathrm{G}$ and homozygous $1 \mathrm{G} / 1 \mathrm{G}$ were associated with decreased risk of childhood ALL ( $p=0.0395$ and $0.0013, \mathrm{OR}=0.68$ and $0.43,95 \% \mathrm{CI}=0.47-0.98$ and 0.26 0.73 , respectively; Table II). In the recessive and dominant 
Table I. Selective demographic information of 266 childhood acute lymphoblastic leukemia cases and 266 matched controls.

\begin{tabular}{|c|c|c|c|c|c|c|c|}
\hline \multirow[t]{2}{*}{ Characteristic } & \multicolumn{3}{|c|}{ Controls $(n=266)$} & \multicolumn{3}{|c|}{ Cases $(n=266)$} & \multirow[t]{2}{*}{$p$-Value } \\
\hline & $\mathrm{n}$ & $\%$ & Mean (SD) & $\mathrm{n}$ & $\%$ & Mean (SD) & \\
\hline Age at onset & & & $8.3(4.8)$ & & & $7.0(4.4)$ & $0.64^{\mathrm{a}}$ \\
\hline$<3.5$ years & 133 & $50.0 \%$ & & 133 & $50.0 \%$ & & \\
\hline$\geq 3.5$ years & 133 & $50.0 \%$ & & 133 & $50.0 \%$ & & $1.00^{\mathrm{b}}$ \\
\hline \multicolumn{8}{|l|}{ Gender } \\
\hline Male & 148 & $55.6 \%$ & & 148 & $55.6 \%$ & & \\
\hline Female & 118 & $44.4 \%$ & & 118 & $44.4 \%$ & & $1.00^{\mathrm{b}}$ \\
\hline
\end{tabular}

aBased on Student's $t$-test; bbased on Chi-square test.

Table II. Analysis of the metalloproteinase 1 rs 1799750 genotypic and allelic frequencies among 266 childhood acute lymphoblastic leukemia cases and 266 healthy controls.

\begin{tabular}{|c|c|c|c|c|c|c|}
\hline Genotype & Controls & $\%$ & Cases & $\%$ & $p$-Value ${ }^{\mathrm{a}}$ & OR $(95 \%$ CI $)$ \\
\hline \multicolumn{7}{|l|}{ Genotype analysis } \\
\hline $2 \mathrm{G} / 2 \mathrm{G}$ & 98 & $36.8 \%$ & 131 & $49.2 \%$ & & 1.00 (Reference) \\
\hline $1 \mathrm{G} / 2 \mathrm{G}$ & 116 & $43.6 \%$ & 105 & $39.5 \%$ & 0.0395 & $0.68(0.47-0.98)$ \\
\hline $1 \mathrm{G} / 1 \mathrm{G}$ & 52 & $19.5 \%$ & 30 & $11.3 \%$ & 0.0013 & $0.43(0.26-0.73)$ \\
\hline \multirow{2}{*}{\multicolumn{7}{|c|}{ Carrier comparison }} \\
\hline & & & & & & \\
\hline $2 \mathrm{G} / 2 \mathrm{G}+1 \mathrm{G} / 2 \mathrm{G}$ & 214 & $80.5 \%$ & 236 & $88.6 \%$ & & 1.00 (Reference) \\
\hline $1 \mathrm{G} / 1 \mathrm{G}$ & 52 & $19.5 \%$ & 30 & $11.3 \%$ & 0.0083 & $0.52(0.32-0.85)$ \\
\hline $2 \mathrm{G} / 2 \mathrm{G}$ & 98 & $36.8 \%$ & 131 & $49.2 \%$ & & 1.00 (Reference) \\
\hline $1 \mathrm{G} / 1 \mathrm{G}+1 \mathrm{G} / 2 \mathrm{G}$ & 168 & $63.2 \%$ & 135 & $50.8 \%$ & 0.0039 & $0.60(0.43-0.85)$ \\
\hline
\end{tabular}

OR: Odds ratio; CI: confidence interval. aBased on Pearson's Chi-square test. Statistically significant differences are shown in bold.

models, there was still significant association between the genotype of $M M P 1$ rs1799750 and childhood ALL risk $(p=0.0083$ and $0.0039, \mathrm{OR}=0.53$ and $0.60,95 \% \mathrm{CI}=0.32-0.85$ and $0.43-0.85$, respectively; Table II). The conclusion that can be deduced from Table II is that the MMP1 rs1799750 1G/2G and $1 \mathrm{G} / 1 \mathrm{G}$ genotypes ( $1 \mathrm{G}$ allele) seemed to be a protective factor for childhood ALL in Taiwanese.

Because age and gender are the predominant risk factors for developing childhood ALL, the contribution of the MMP1 rs1799750 genotype to childhood ALL stratified by age and gender were further analyzed and the results or presented in Table III. The average median age of onset of ALL in the control and patient groups was 3.5 years; thus, we further stratified the groups into subgroups of those $<3.5$ and $\geq 3.5$ year-old. Notably, in the younger sub-group, those with heterozygous $1 \mathrm{G} / 2 \mathrm{G}$ or homozygous $1 \mathrm{G} / 1 \mathrm{G}$ genotype for MMPl rs1799750 had lower risk for developing childhood ALL than those with the wild-type $2 \mathrm{G} / 2 \mathrm{G}$ genotype ( $\mathrm{p}$ for trend $=0.0008, p=0.0183$ and $0.0004 ; \mathrm{OR}=0.53$ and $0.25,95 \% \mathrm{CI}=0.31-0.90$ and 0.12 -
0.56 for $1 \mathrm{G} / 2 \mathrm{G}$ and $1 \mathrm{G} / 1 \mathrm{G}$, respectively), and the combined group of those carrying $1 \mathrm{G} M M P 1$ rs1799750 genotypes also gave similar results $(\mathrm{OR}=0.44,95 \%$ $\mathrm{CI}=0.27-0.72 ; p=0.0009)$; however, there was no any significant association found in the analysis of the older sub-group (Table III).

For gender, males with $1 \mathrm{G} / 2 \mathrm{G}$ or $1 \mathrm{G} / 1 \mathrm{G}$ genotypes for MMP1 rs1799750 were less likely to develop childhood ALL than those with the homozygous $2 \mathrm{G} / 2 \mathrm{G}$ genotype ( $p$ for trend $=0.0014 ; \mathrm{OR}=0.57$ and $0.24,95 \% \mathrm{CI}=0.34-0.95$ and $0.10-0.56 ; p=0.0318$ and 0.0005 for $1 \mathrm{G} / 2 \mathrm{G}$ and $1 \mathrm{G} / 1 \mathrm{G}$, respectively), and the combined group of those carrying $1 \mathrm{G}$ MMP1 rs1799750 genotypes also gave similar results $(\mathrm{OR}=0.47,95 \% \mathrm{CI}=0.29-0.76 ; p=0.0021)$. However, there was no significant association found in the analysis of the female sub-group (Table III).

In summary, the results of stratification analysis revealed an interaction between a younger age at onset and being male with MMP1 rs1799750 genotype in susceptibility to childhood ALL. 
Table III. Distribution of the metalloproteinase 1 (MMP1) rs1799750 genotypes stratified by age and gender among 266 childhood acute lymphoblastic leukemia cases and 266 healthy controls.

\begin{tabular}{|c|c|c|c|c|c|}
\hline \multirow[b]{2}{*}{ Characteristic } & \multicolumn{3}{|c|}{ MMP1 rs1799750 } & \multirow[b]{2}{*}{$p$-Value } & \multirow[b]{2}{*}{ OR $(95 \% \mathrm{CI})$} \\
\hline & Controls n (\%) & Cases n (\%) & $p_{\text {trend }}{ }^{\mathrm{a}}$ & & \\
\hline \multicolumn{6}{|l|}{ Age at onset } \\
\hline$<3.5$ years & & & 0.0008 & & \\
\hline $2 \mathrm{G} / 2 \mathrm{G}$ & $49(36.8)$ & $76(57.1)$ & & & 1.00 (Reference) \\
\hline $1 \mathrm{G} / 2 \mathrm{G}$ & $56(42.1)$ & $46(34.6)$ & & 0.0183 & $0.53(0.31-0.90)$ \\
\hline $1 \mathrm{G} / 1 \mathrm{G}$ & $28(21.1)$ & $11(8.3)$ & & 0.0004 & $0.25(0.12-0.56)$ \\
\hline $1 \mathrm{G} / 2 \mathrm{G}+1 \mathrm{G} / 1 \mathrm{G}$ & $84(63.2)$ & $57(42.9)$ & & 0.0009 & $0.44(0.27-0.72)$ \\
\hline$\geq 3.5$ years & & & 0.6263 & & \\
\hline $2 \mathrm{G} / 2 \mathrm{G}$ & $49(36.8)$ & $55(41.3)$ & & & 1.00 (Reference) \\
\hline $1 \mathrm{G} / 2 \mathrm{G}$ & $60(45.1)$ & $59(44.4)$ & & 0.6224 & $0.88(0.52-1.48)$ \\
\hline $1 \mathrm{G} / 1 \mathrm{G}$ & $24(18.1)$ & $19(14.3)$ & & 0.3373 & $0.71(0.35-1.44)$ \\
\hline $1 \mathrm{G} / 2 \mathrm{G}+1 \mathrm{G} / 1 \mathrm{G}$ & $84(63.2)$ & $78(58.7)$ & & 0.4509 & $0.83(0.51-1.35)$ \\
\hline \multicolumn{6}{|l|}{ Gender } \\
\hline Male & & & 0.0014 & & \\
\hline $2 \mathrm{G} / 2 \mathrm{G}$ & $51(38.3)$ & $76(57.1)$ & & & 1.00 (Reference) \\
\hline $1 \mathrm{G} / 2 \mathrm{G}$ & $57(42.9)$ & $48(36.1)$ & & 0.0318 & $0.57(0.34-0.95)$ \\
\hline $1 \mathrm{G} / 1 \mathrm{G}$ & $25(18.8)$ & $9(6.8)$ & & 0.0005 & $0.24(0.10-0.56)$ \\
\hline $1 \mathrm{G} / 2 \mathrm{G}+1 \mathrm{G} / 1 \mathrm{G}$ & $82(61.7)$ & $57(42.9)$ & & 0.0021 & $0.47(0.29-0.76)$ \\
\hline Female & & & 0.4936 & & \\
\hline $2 \mathrm{G} / 2 \mathrm{G}$ & $47(35.3)$ & $55(41.3)$ & & & 1.00 (Reference) \\
\hline $1 \mathrm{G} / 2 \mathrm{G}$ & $59(44.4)$ & $57(42.9)$ & & 0.4807 & $0.83(0.48-1.41)$ \\
\hline $1 \mathrm{G} / 1 \mathrm{G}$ & $27(20.3)$ & $21(15.8)$ & & 0.2451 & $0.66(0.33-1.33)$ \\
\hline $1 \mathrm{G} / 2 \mathrm{G}+1 \mathrm{G} / 1 \mathrm{G}$ & $86(64.7)$ & $78(55.93)$ & & 0.3131 & $0.78(0.47-1.27)$ \\
\hline
\end{tabular}

OR, Odds ratio; CI, confidence interval. aBased on Chi-square test. Statistically significant differences are shown in bold.

\section{Discussion}

In the current study, we firstly examined the contribution of MMPI genotype to childhood ALL susceptibility. Since MMP1 plays an essential role in angiogenesis and metastasis via its regulatory function in the extracellular matrix, it is very possible that hereditary genomic variations may determine personal susceptibility to carcinogenesis. In literature, the polymorphic $M M P 1$ genotype at $-1,603$ (rs1799750) may determine the $M M P 1 \mathrm{mRNA}$ and protein levels, and the susceptibility to cancer (25). Head and neck squamous carcinoma cells with the $2 \mathrm{G} / 2 \mathrm{G}$ genotype were found to express significantly more $M M P 1$ mRNA than those with $1 \mathrm{G} / 2 \mathrm{G}$ or $1 \mathrm{G} / 1 \mathrm{G} M M P 1$ rs 1799750 genotypes. Moreover, the $2 \mathrm{G}$ allele of $M M P 1$ rs1799750 is associated with the risk of several types of cancer, including oral (12), breast (13), gastric (18), colorectal (26) and bladder (27). In addition, a negative association was also found in ovarian (14) and lung (15) cancer. However, little is known about the association between $M M P 1$ genotype and the risk of leukemia, which is a nonsolid type of cancer.

In the current study, we found that the $1 \mathrm{G} / 1 \mathrm{G}$ homozygous and $1 \mathrm{G} / 2 \mathrm{G}$ heterozygous genotypes of $M M P 1$ rs1799750 were significantly associated with a lower susceptibility to childhood ALL (Table II). As far as we are aware of, the current study is the first to reveal the genotypic contribution of MMP1 genotypes to (childhood) ALL, with the novel findings that MMP1 rs1799750 may be a potential marker for prediction of childhood ALL (Table II).

The MMP1 protein is involved in the degradation of the native collagens in extracellular matrix (ECM). Under normal conditions, MMP1 is expressed at a relatively low level under the see-saw regulation of TIMP1 protein $(28,29)$. In addition, MMP1 has been reported to play a critical role in the invasion and migration processes of solid tumors $(30,31)$. Furthermore, mounting evidence indicates that up-regulation of MMP1 is observed in the borders of solid tumors, such as in breast and oral cancer (32-34). In 2010, Scrideli and colleagues collected bone marrow samples from 134 children with ALL and evaluated the mRNA expression profile of TIMP1, TIMP2, $M M P 2$ and MMP9. They found that TIMP1 gene expression values higher than the median were associated with a significantly lower 5-year event free-survival, indicating that a high TIMP1 level may be a potential marker for poor prognosis of ALL (35). It is still controversial whether MMP1 expression is lower in those tissues with higher TIMP1 expression, and is likely to be associated with significantly 
lower 5-year event free-survival and poorer prognosis. Moreover, revealing the contribution of TIMP1 genotypes to childhood ALL and the detail mechanisms and crosstalk between TIMP1 and MMP1 may help our further understanding of the tissue microenvironmental alterations during ALL progression.

In the current study, we further analyzed the influence of MMP1 rs1799750 genotype on childhood ALL susceptibility according to the age of onset and gender of the investigated children. Children in the early onset subgroup, aged less than 3.5 years, had a lower risk of childhood ALL with $1 \mathrm{G} / 2 \mathrm{G}$ or $1 \mathrm{G} / 1 \mathrm{G}$ MMP1 rs 1799750 genotypes than those with wild-type $2 \mathrm{G} / 2 \mathrm{G}$ genotype. However, this difference was not found for the older subgroup of children (Table III). We also found that boys with $1 \mathrm{G} / 2 \mathrm{G}$ or $1 \mathrm{G} / 1 \mathrm{G} M M P 1$ rs 1799750 genotypes had a lower risk of childhood ALL than those with the wild-type $2 \mathrm{G} / 2 \mathrm{G}$ genotype. At the same time, although no statistically significant association was found in the analysis of MMPI rs1799750 genotypes among girls, there was a similar protective role of 1G-carrying MMP1 rs1799750 genotypes (Table III). Future investigation with a larger sample size may confirm the findings for the gender difference in the contribution of $M M P 1$ rs1799750 genotype to ALL susceptibility among boys and girls. In the current study, it seems that the protective impact of the $1 \mathrm{G}$ allele at MMP1 rs 1799750 with respect to ALL risk was more obvious for Taiwanese boys than girls (Table III). Similarly in our previous findings, the A allele for flap endonuclease 1 rs174538 was also protective against childhood ALL, and the association was again only significant in boys but not girls (22). In searching for the different effects of sex hormones on leukemia cells, it was found that $17-\beta$ estrogen induced a significant increase of apoptosis in macrophage-like U937 cells, but testosterone did not (36). On the contrary, progesterone, but not $17-\beta$-estradiol, increases the secretion of tumor necrosis factor $\alpha$ in U937 cells, inducing the death of the cells by another pathway (37). The different roles of sexual hormones in childhood ALL need more investigation.

In conclusion, this study documented the evidence of a positive association between the genotype of MMP1 rs1799750 and childhood ALL in addition to age and gender interactions with the MMP1 rs1799750 genotype in determining childhood ALL susceptibility. The presence of the $1 \mathrm{G}$ allele at MMP1 rs 1799750 was not only a novel predictive biomarker for childhood ALL but also a protective determinant for boys and patients younger than 3.5 years.

\section{Conflicts of Interest}

The Authors declare no interest conflict with any person or company.

\section{Acknowledgements}

This study was supported by research grants from Taoyuan General Hospital, Ministry of Health and Welfare, Taiwan, ROC (grant number: PTH10519) and the Taiwan Ministry of Health and Welfare Clinical Trial and Research Center of Excellence (MOHW 105TDU-B-212-133019). The technical assistance from Chung-Hao Su, Hsin-Ting Li and Shiou-Ting Yen is highly appreciated by the Authors.

\section{References}

1 Digilio G and Digilio M: Medical progress, psychological factors and global care of the patient: lessons from the treatment of childhood leukemia. Ann Ist Super Sanita 49: 92-96, 2013.

2 Kaatsch P: Epidemiology of childhood cancer. Cancer Treat Rev 36: 277-285, 2010

3 Barry EV and Silverman LB: Acute lymphoblastic leukemia in adolescents and young adults. Curr Hematol Malig Rep 3: 161166, 2008.

4 Belson M, Kingsley B and Holmes A: Risk factors for acute leukemia in children: a review. Environ Health Perspect 115: 138-145, 2007.

5 Zwaan CM, Reinhardt D, Hitzler J and Vyas P: Acute leukemias in children with Down syndrome. Hematol Oncol Clin North Am 24: 19-34, 2010.

6 Mathew CG: Fanconi anaemia genes and susceptibility to cancer. Oncogene 25: 5875-5884, 2006.

7 Szczepanski T, Harrison CJ and van Dongen JJ: Genetic aberrations in paediatric acute leukaemias and implications for management of patients. Lancet Oncol 11: 880-889, 2010.

8 Tishkoff DX, Filosi N, Gaida GM and Kolodner RD: A novel mutation avoidance mechanism dependent on $S$. cerevisiae RAD27 is distinct from DNA mismatch repair. Cell 88: 253-263, 1997.

9 Parrish JZ, Yang C, Shen B and Xue D: CRN-1, a Caenorhabditis elegans fen-1 homologue, cooperates with CPS6/EndoG to promote apoptotic DNA degradation. EMBO J 22: 3451-3460, 2003.

10 Zheng L, Dai H, Zhou M, Li M, Singh P, Qiu J, Tsark W, Huang Q, Kernstine K, Zhang X, Lin D and Shen B: FEN1 mutations result in autoimmunity, chronic inflammation and cancers. Nat Med 13: 812-819, 2007.

11 Yang M, Guo H, Wu C, He Y, Yu D, Zhou L, Wang F, Xu J, Tan W, Wang G, Shen B, Yuan J, Wu T and Lin D: Functional FEN1 polymorphisms are associated with DNA damage levels and lung cancer risk. Hum Mutat 30: 1320-1328, 2009.

12 Sun KT, Tsai CW, Chang WS, Shih LC, Chen LY, Tsai MH, Ji HX, Hsiao CL, Liu YC, Li CY and Bau DT: The contribution of matrix metalloproteinase-1 genotype to oral cancer susceptibility in Taiwan. In Vivo 30: 439-444, 2016.

$13 \mathrm{Su}$ CH, Lane HY, Hsiao CL, Liu LC, Ji HX, Li HT, Yen ST, Su $\mathrm{CH}$, Hsia TC, Chang WS, Tsai CW and Bau DT: Matrix metalloproteinase-1 genetic polymorphism in breast cancer in Taiwanese. Anticancer Res 36: 3341-3345, 2016.

14 Wang L and Kong B: Analysis of the association of matrix metalloproteinase-1 gene promoter (rs 1799750) polymorphism and risk of ovarian cancer. Int J Gynecol Cancer 25: 961-967, 2015. 
15 Fakhoury H, Noureddine S, Chmaisse HN, Tamim H and Makki RF: MMP1-1607(1G>2G) polymorphism and the risk of lung cancer in Lebanon. Ann Thorac Med 7: 130-132, 2012.

16 Guan X, Wang X, Luo H, Wu J, Zhang X and Wu J: Matrix metalloproteinase 1,3, and 9 polymorphisms and esophageal squamous cell carcinoma risk. Med Sci Monit 20: 2269-2274, 2014.

$17 \mathrm{Li} \mathrm{Z}$, Ge H, Xie YG, Xie GY and Lv C: Matrix metalloproteinase-1 (MMP1) polymorphism is associated with lowered risk of nasopharyngeal carcinoma in Asian population. Cell Biochem Biophys 71: 999-1004, 2015.

18 Peng $\mathrm{Q}$ and $\mathrm{Xu} \mathrm{Y}$ : Association between promoter polymorphisms of matrix metalloproteinase-1 and risk of gastric cancer. Onco Targets Ther 8: 2519-2526, 2015.

19 Liu D, Duan W, Guo H, Xu X and Bai Y: Meta-analysis of associations between polymorphisms in the promoter regions of matrix metalloproteinases and the risk of colorectal cancer. Int J Colorectal Dis 26: 1099-1105, 2011.

20 Pei JS, Lee YM, Lo HH, Hsu YN, Lin SS and Bau DT: Association of X-ray repair cross-complementing-6 genotypes with childhood leukemia. Anticancer Res 33: 5395-5399, 2013.

21 Pei JS, Hsu CM, Tsai CW, Chang WS, Ji HX, Hsiao CL, Miao CE, Hsu YN and Bau DT: The association of methylenetetrahydrofolate reductase genotypes with the risk of childhood leukemia in Taiwan. PLoS One 10: e0119776, 2015.

22 Pei JS, Chang WS, Hsu PC, Tsai CW, Hsu CM, Ji HX, Hsiao CL, Hsu YN and Bau DT: The association of flap endonuclease 1 genotypes with the risk of childhood leukemia. Cancer Genomics Proteomics 13: 69-74, 2016.

23 Chang $\mathrm{CH}$, Chiu CF, Liang SY, Wu HC, Chang CL, Tsai CW, Wang HC, Lee HZ and Bau DT: Significant association of Ku80 single nucleotide polymorphisms with bladder cancer susceptibility in Taiwan. Anticancer Res 29: 1275-1279, 2009.

24 Bau DT, Yang MD, Tsou YA, Lin SS, Wu CN, Hsieh HH, Wang RF, Tsai CW, Chang WS, Hsieh HM, Sun SS and Tsai RY: Colorectal cancer and genetic polymorphism of DNA doublestrand break repair gene XRCC4 in Taiwan. Anticancer Res 30: 2727-2730, 2010.

$25 \mathrm{P}$ Oc, Leksrisakul $\mathrm{P}$ and Sangruchi S: A functional polymorphism in the matrix metalloproteinase- 1 gene promoter is associated with susceptibility and aggressiveness of head and neck cancer. Int J Cancer 118: 2548-2553, 2006.

26 Woo M, Park K, Nam J and Kim JC: Clinical implications of matrix metalloproteinase-1, -3, -7, -9, -12, and plasminogen activator inhibitor-1 gene polymorphisms in colorectal cancer. $\mathrm{J}$ Gastroenterol Hepatol 22: 1064-1070, 2007.

27 Srivastava P, Gangwar R, Kapoor R and Mittal RD: Bladder cancer risk associated with genotypic polymorphism of the matrix metalloproteinase-1 and -7 in North Indian population. Dis Markers 29: 37-46, 2010.
28 Nagase H and Woessner JF Jr.: Matrix metalloproteinases. J Biol Chem 274: 21491-21494, 1999.

29 Surlin V, Ioana $M$ and Plesea IE: Genetic patterns of metalloproteinases and their tissular inhibitors - clinicopathologic and prognostic significance in colorectal cancer. Rom J Morphol Embryol 52: 231-236, 2011.

30 Kessenbrock K, Plaks V and Werb Z: Matrix metalloproteinases: regulators of the tumor microenvironment. Cell 141: 52-67, 2010.

31 Roy R, Yang J and Moses MA: Matrix metalloproteinases as novel biomarkers and potential therapeutic targets in human cancer. J Clin Oncol 27: 5287-5297, 2009.

32 Boire A, Covic L, Agarwal A, Jacques S, Sherifi S and Kuliopulos A: PAR1 is a matrix metalloprotease-1 receptor that promotes invasion and tumorigenesis of breast cancer cells. Cell 120: 303-313, 2005.

33 George A, Ranganathan K and Rao UK: Expression of MMP-1 in histopathological different grades of oral squamous cell carcinoma and in normal buccal mucosa - an immunohistochemical study. Cancer Biomark 7: 275-283, 2010.

34 Zhou J, Brinckerhoff C, Lubert S, Yang K, Saini J, Hooke J, Mural R, Shriver C and Somiari S: Analysis of matrix metalloproteinase-1 gene polymorphisms and expression in benign and malignant breast tumors. Cancer Invest 29: 599-607, 2011.

35 Scrideli CA, Cortez MA, Yunes JA, Queiroz RG, Valera ET, da Mata JF, Toledo SR, Pavoni-Ferreira P, Lee ML, Petrilli AS, Brandalise SR and Tone LG: mRNA expression of matrix metalloproteinases (MMPs) 2 and 9 and tissue inhibitor of matrix metalloproteinases (TIMPs) 1 and 2 in childhood acute lymphoblastic leukemia: potential role of TIMP1 as an adverse prognostic factor. Leuk Res 34: 32-37, 2010.

36 Carruba G, D'Agostino P, Miele M, Calabro M, Barbera C, Bella GD, Milano S, Ferlazzo V, Caruso R, Rosa ML, Cocciadiferro L, Campisi I, Castagnetta L and Cillari E: Estrogen regulates cytokine production and apoptosis in PMA-differentiated, macrophage-like U937 cells. J Cell Biochem 90: 187-196, 2003.

37 Jain SK, Kannan K, Prouty L and Jain SK: Progesterone, but not 17beta-estradiol, increases TNF-alpha secretion in U937 monocytes. Cytokine 26: 102-105, 2004.
Received September 8, 2016

Revised September 27, 2016

Accepted September 28, 2016 